\title{
Nijmegen breakage syndrome
}

\author{
Ineke van der Burgt, Krystyna H Chrzanowska, Dominique Smeets, Corry Weemaes
}

\begin{abstract}
Nijmegen breakage syndrome (NBS), a rare autosomal recessive condition also known as ataxia telangiectasia (AT) variants $\mathrm{V} 1$ and $\mathrm{V} 2$, is characterised by microcephaly, typical facies, short stature, immunodeficiency, and chromosomal instability. We report the clinical, immunological, chromosomal, and cell biological findings in 42 patients who are included in the NBS Registry in Nijmegen. The immunological, chromosomal, and cell biological findings resemble those in AT, but the clinical findings are quite different. NBS appears to be a separate entity not allelic with AT.

(f Med Genet 1996;33:153-156)
\end{abstract}

Key words: Nijmegen breakage syndrome; ataxia telangiectasia.

Nijmegen breakage syndrome (NBS) is a rare autosomal recessive condition, characterised by microcephaly, typical face, short stature, chromosomal instability, and immunodeficiency accompanied by recurrent infections and predisposition to malignancies (MIM No 251260). Since the recognition of the first two patients in $1981,{ }^{1}$ we have included 42 patients in our NBS Registry in Nijmegen. ${ }^{1-11}$ The disease appears to be prevalent among the eastern and central European population, in particular among the Polish people. ${ }^{23}$ Although the immunological, cytogenetic, and cell biological findings in NBS resemble those in ataxia telangiectasia (AT), the clinical findings are quite different. NBS has been proposed as an allelic form of AT and designated as an AT variant with two complementation groups, V1 and V2.

Recently the gene for AT on chromosone 11q22-23 has been identified (ATM = AT mutated) and found to be mutated in AT patients from all four complementation groups. ${ }^{12}$ At present there is little information on the possible chromosomal location of the NBS gene(s). The AT locus, however, has been excluded from harbouring the NBS gene. ${ }^{113-15}$

\section{Clinical description}

GROWTH AND DEVELOPMENT

The growth retardation in NBS patients can be of pre- or postnatal onset. In $70 \%$ of patients, birth weight and birth length conform to gest- ational age. The head circumference (OFC) at birth varies between $26.5 \mathrm{~cm}$ and $36 \mathrm{~cm} ; 75 \%$ of patients are born with an OFC below the 3rd centile. This implies that not all patients are microcephalic at birth. However, they all develop progressive and severe microcephaly during the first months of life. ${ }^{3}$ Height falls below the 10 th centile in all patients. From the first stages of development onwards growth retardation is observed. After a few years a slight improvement is seen and height is on average almost on the 3 rd centile. The growth retardation is proportionate and weight corresponds to length. Bone age can be somewhat retarded. ${ }^{3}$ Little is known about the sexual maturation of patients with NBS. The only endocrinological abnormality described as yet is ovarian dysgenesis in two patients ${ }^{4}$ (K Chrzanowska, personal communication).

Developmental milestones are mostly not delayed during the first year of life. Mental development is normal in $35 \%$ of NBS patients, $45 \%$ have borderline retardation, while $20 \%$ are moderately retarded.

None of the patients has signs of cerebellar ataxia, apraxic eye movements, or other neurological abnormalities, except for two girls described by Curry et $a l^{7}$ who had clinical symptoms of both NBS and AT. Their condition was considered to be an AT variant and referred to as "ATFresno", representing a distinct entity. ${ }^{16}$ Complementation studies performed in 1988 assigned these twin sisters to NBS complementation group V1. ${ }^{7}$

\section{CRANIOFACIAL FINDINGS}

The craniofacial characteristics become more obvious with age. ${ }^{23}$ This is probably also because of the progressive and severe microcephaly in all patients. The hair becomes sparse in half of the NBS patients. The face is characterised by a receding forehead, prominent midface with a long nose and long philtrum, receding mandible, upward slanting palpebral fissures, large ears with dysplastic helices, and freckles on the cheeks and nose (figs 1 and 2). Subtle scleral telangiectasia can be present; this has been noted in 10 out of 25 patients. ${ }^{37}$

\section{SKIN}

Pigmentation abnormalities are present in most patients. Freckles are mostly seen on the face. 

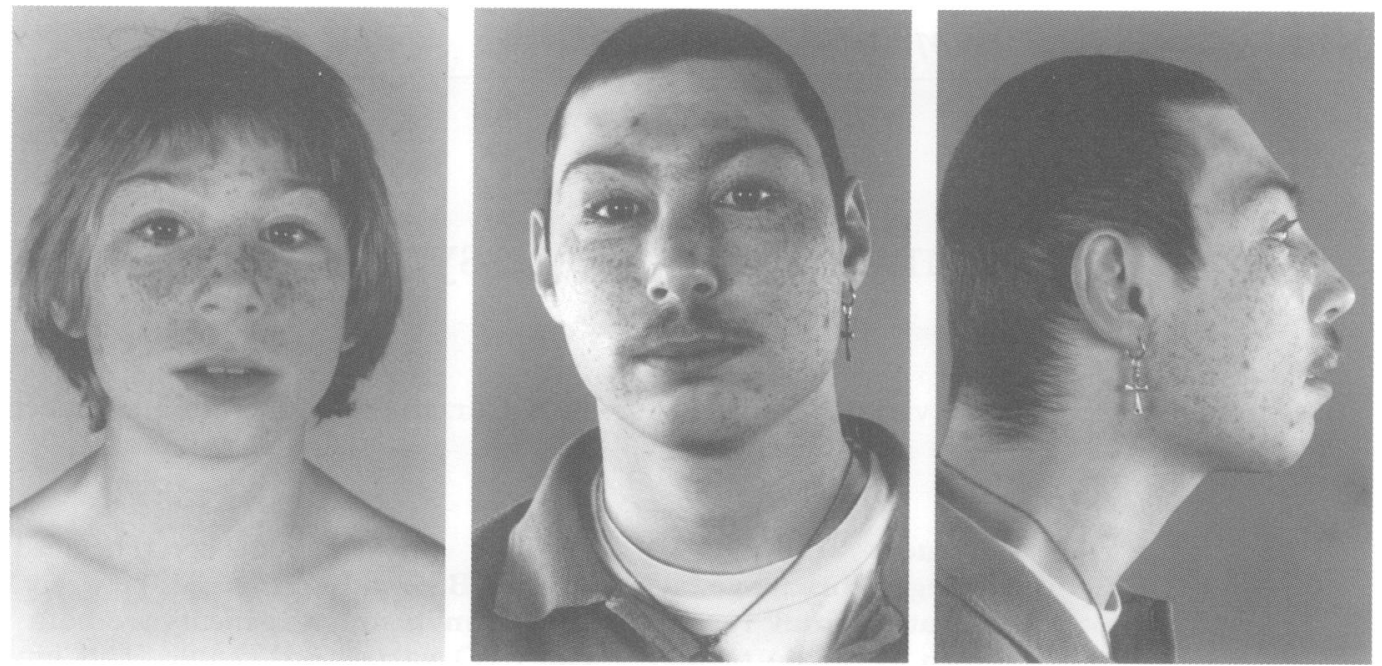

Figure 1 Patient from Weemaes et al (left) at 9 years of age and (centre and right) at 24 years of age. Note the microcephaly, receding forehead, slightly upward slanting palpebral fissures, freckles, and prominent midface.

Two to five café au lait-like spots are found in half of the patients and most also have some vitiligo spots. Cutaneous telangiectasia have been noted in only two patients. ${ }^{38}$ Sun sensitivity of the eyelids can be present. ${ }^{23}$

\section{CONGENITAL MALFORMATIONS}

Congenital malformations reported once each are: preaxial polydactyly, ${ }^{3}$ occipital cyst $^{10}$ hydrocephalus, ${ }^{6}$ choanal atresia, ${ }^{2}$ cleft lip and palate, ${ }^{2}$ hypospadias, ${ }^{11}$ and a single ectopic kidney. ${ }^{3}$ In three patients anal atresia was present at birth, ${ }^{35}$ and in another three patients hydronephrosis has been diagnosed. ${ }^{26}$

\section{INFECTIONS}

Respiratory tract infections occur in almost all patients with NBS. Pneumonia, bronchitis, otitis media, sinusitis, and mastoiditis are frequently seen. Complications such as bronchiectasis, respiratory insufficiency, and even
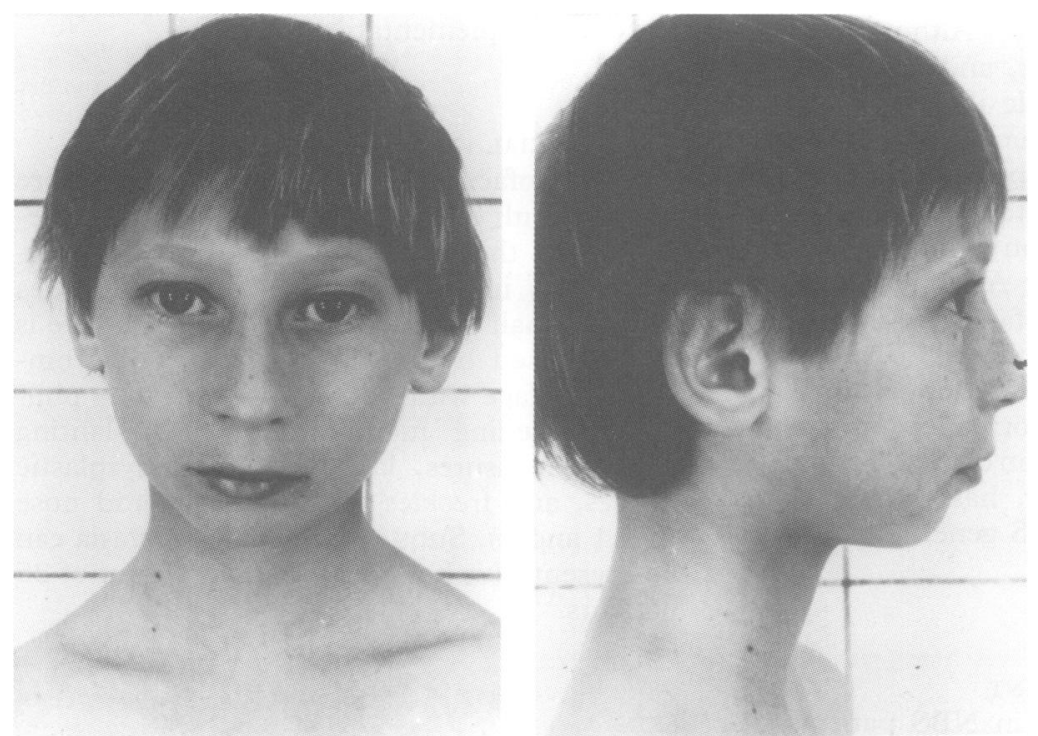

Figure 2 Typical facial features in an 8 year old boy with microcephaly, long prominent nose, and small chin. death from respiratory failure can ocur. In three patients no respiratory tract infections were reported, but two of them were only 8 and 18 months old at the time of reporting. ${ }^{11}$ The other patient is a 4 year old girl who had no disturbance of her cellular immunity. ${ }^{8}$ Urinary tract infections repeatedly occur in $15 \%$ of patients with NBS. Gastrointestinal infections with diarrhoea have also been mentioned in $15 \%$ of patients.

\section{PREDISPOSITION TO MALIGNANCIES}

Both immunodeficiency and chromosome instability probably predispose to malignancies. In NBS patients there is a tendency to develop lymphomas at a young age. So far, 12 patients varying in age from 1 to 22 years have developed a lymphoma. One patient developed a glioma at the age of 12 years, one patient a medulloblastoma at 15 years, and one patient a rhabdomyosarcoma at 4 years. Two patients who developed a lymphoma are still alive, the others died within a few months to years after the malignancy had been diagnosed. When treating malignancies in these patients, cytostatics should be the first choice. However, radiomimetics (for example, bleomycin) should be avoided, and the chemotherapy doses should be reduced. ${ }^{17}$ Radiation therapy should also be avoided, since $x$ irradiation can induce malignancies in NBS patients. If necessary, as can be the case in solid tumours, an estimation of the individual dose is recommended. ${ }^{18}$

\section{NECROPSY FINDINGS}

Of the 42 patients included in the NBS registry 15 have died, four patients from bronchopneumonia, 10 from lymphoid malignancy, and one patient who developed a medulloblastoma. An extensive necropsy was performed on only one patient. ${ }^{19}$ In this patient important findings were the extremely reduced brain weight and the absence of diffuse cortical cerebellar degeneration, the presence of which is characteristic of AT. The thymus showed 
simple dysplasia. Limited necropsy data from other patients confirm thymus dysplasia or even thymus aplasia. ${ }^{2}$

\section{Immunological disturbances}

The immune deficiency in NBS patients is relatively severe and concerns the humoral and cellular immune system. The humoral immunodeficiency is characterised by disturbed serum immunoglobulins; agammaglobulinaemia, IgA deficiency, and IgG2 and IgG4 deficiency can be found. In one patient immunological attrition was noticed. As well as IgA deficiency that he had had for years, he developed agammaglobulinaemia at 24 years of age, after he had been treated with cytostatics for a lymphoma. ${ }^{20}$ The defective cellular immunity is characterised by mild to moderate lymphopenia with decreased $\mathrm{CD} 3+$ and $\mathrm{CD} 4+$ (helper) cells and a decreased CD4+ $\mathrm{CD} 8+$ (suppressor) cell ratio. The in vitro response of lymphocytes to mitogens is impaired. The patient described by Barbi et at was the only one reported to have normal $T$ cell immunity and had no recurrent infections at the age of 4 years. ${ }^{8}$

\section{Cytogenetic features}

NBS patients basically have a normal karyotype. Cultured $\mathrm{T}$ lymphocytes often show an extremely low mitotic index, in which case cytogenetic analysis can be very difficult. In all patients structural chromosome aberrations are present in 10 to $35 \%$ of metaphases of cultured $\mathrm{T}$ cells. Most of the rearrangements preferentially occur in chromosomes 7 or 14 or both at bands $7 \mathrm{p} 13,7 \mathrm{q} 35,14 \mathrm{q} 11$, and $14 \mathrm{q} 32$, the same breakpoints as found in AT. These breakpoints coincide with the location of genes having immune function. ${ }^{21}$

$\operatorname{Inv}(7)(\mathrm{p} 13 \mathrm{q} 35)$ is the most frequently detected aberration in NBS. Other rearrangements are $t(7 ; 14)(p 13 ; q 11), t(7 ; 14)$ (q35;q11), t $(7 ; 7)$ (p13;q35), and $\mathrm{t}(14 ; 14)$ (q11; q32).

$\operatorname{Inv}(14)(\mathrm{q} 11 \mathrm{q} 32)$ had not been found in NBS patients until recently when it was detected in a lymphocyte culture of a 24 year old patient. ${ }^{20}$ In fibroblasts, chromatid type instability has been observed. ${ }^{1358}$ In one case chromosomal rearrangements were found in $33 \%$ of fibroblasts, but without involvement of chromosomes 7 or $14 .^{4}$ No chromosomal instability has been observed in bone marrow cells. ${ }^{1}$

\section{Alphafetoprotein (AFP) levels}

Serum AFP levels are normal in NBS patients, in contrast to AT patients, in whom an increased serum AFP level is one of the hallmarks. The only patients with abnormally increased serum AFP levels are the twins with ATFresno, assigned to NBS complementation group $\mathrm{V} 1 .^{7}$ In two patients, serum AFP levels were raised at the age of 5 months, but decreased to normal by 15 months and 2 years respectively. ${ }^{38}$
Radioresistant DNA synthesis (RDS) and radiation hypersensitivity

Increased sensitivity of both lymphocytes and fibroblasts from NBS patients to ionising radiation or to radiomimetics, and radioresistance of DNA replication, have been established. So far, all patients tested have shown an abnormally increased rate of cell death and chromosome damage after $x$ or gamma irradiation. The inhibition of DNA synthesis after $x$ or gamma irradiation is two to three times less pronounced than in normal cells. ${ }^{3622}$ The results are indistinguishable from AT.

\section{Genetics and molecular studies}

NBS is an autosomal recessive condition. It has been diagnosed in at least 42 patients, 23 males and 19 females from 29 families. The NBS Registry contains 12 sibships among the 42 patients included.

NBS seems to be more prevalent among the Polish people. Twenty-one of the 42 patients have been diagnosed by one of the authors (KHC) in Warsaw. The aetiology of NBS is still completely unknown. Because the immunological, cytogenetic, and cell biological findings in NBS are almost the same as in AT, the elucidation of the AT gene would be an important step forwards for unravelling the genetic basis of NBS. Although NBS proved not to be allelic to AT, the gene responsible for NBS may be similar to the ATM (=AT mutated) gene and have comparable functions. The ATM gene on chromosome 11q22-23 was found to be mutated in AT patients from all complementation groups. A partial ATM complementary DNA clone encoded a putative protein with sequence similarities suggesting involvement of the ATM gene product in signal transduction, cellular responses to DNA damage, and cell cycle control functions that are defective in AT. $^{12}$

The observation of non-linkage of NBS with the ATM gene was corroborated by the study of Komatsu, ${ }^{23}$ who found non-complementation of NBS fibroblasts with chromosome 11.

Hitherto, NBS patients have been divided into two different complementation groups, V1 and V2, whereas AT patients have been represented in four other separate groups: A, C, D, and E. ${ }^{1622}$ The characterisation of the ATM gene and convergence of all complementation groups into one gene requires reconsideration of the complementation groups in NBS. NBS is probably also a homogeneous disorder. Knowledge about the ATM gene products and their function could provide important clues for the aetiology of NBS.

\section{Prenatal diagnosis}

As the aetiology of NBS is still unknown, possible methods of prenatal diagnosis must depend on the demonstration of the biochemical findings of the disease. The assessment of spontaneous or radiation induced chromosome aberrations in prenatal tissue has been reported in only a few AT cases. ${ }^{24}$ The disadvantage of 
this method is that a large number of mitoses in chorionic villus (CV) or amniotic fluid (AF) cells have to be analysed. Radioresistant DNA synthesis (RDS) assay on cultured $\mathrm{CV}$ or AF cells has proven to be a reliable method for first trimester prenatal diagnosis of NBS and of AT. The prerequisite for reliable prenatal diagnosis with this method is the demonstration of increased RDS in fibroblasts of the index patient. $^{25}$

\section{Differential diagnosis}

The well known chromosome instability disorders are Fanconi anaemia, Bloom's syndrome, and ataxia telangiectasia. Fanconi anaemia is characterised by short stature, pancytopenia, radial hypoplasia, and brownish hyperpigmentation. Important hallmarks of Bloom's syndrome are severe growth retardation of prenatal onset, sunlight sensitivity leading to telangiectatic erythema, and specific chromosome instability with a high frequency of sister chromatid exchanges. Common findings of both AT and NBS are immunodeficiency, chromosome instability with multiple chromosome 7 or 14 rearrangements, chromosomal hypersensitivity to $x$ rays, and radioresistance of DNA replication. The classical clinical findings in AT are progressive cerebellar ataxia, oculocutaneous telangiectasia, and raised serum AFP levels, which are absent in NBS.

\section{Conclusion}

Because patients with NBS have an increased risk of developing malignancies, it is important to diagnose this disease at an early age. In NBS patients $x$ irradiation should be avoided as much as possible, for therapeutic but also for diagnostic reasons.

In all patients with unexplained early progressive microcephaly and growth retardation, chromosome instability analysis should be performed, in order to establish or exclude a chromosome instability disorder.

1 Weemaes CMR, Hustinx TWJ, Scheres JMJC, van Munster PJJ, Bakkeren JAJM, Taalman RDFM. A new chroPJJ, Bakkeren JAJM, Taalman RDFM. A new chromosomal instability disorder: the Nijmegen breal

2 Seemanova E, Passarge E, Beneskova D, Houstek J, Kasal $P$, Sevcikova M. Familial microcephaly with normal intelligence, immunodeficiency and risk for lymphoreticular malignancies: a new autosomal recessive disorder. $A m \mathcal{F}$ Med Genet 1985;20:639-48.
3 Chrzanowska $\mathrm{KH}$, Kleijer WJ, Krajewska-Walasek M, et al. Eleven Polish patients with microcephaly, immunodeficiency and chromosomal instability; the Nijmegen breakage syndrome. Am $₹$ Med Genet 1995;57:462-71.

4 Conley ME, Spinner NB, Emanuel BS, Nowell PC, Nichols WW. A chromosome breakage syndrome with profound WW. A chromosome breakage syndrome
immunodeficiency. Blood 1986;67:1251-6.

5 Wegner RD, Metzger M, Hanefeld F, et al. A new chromosome instability disorder confirmed by complementation studies. Clin Genet 1988;33:20-32.

6 Taalman RDFM, Hustinx TWJ, Weemaes CMR, et al. Further delineation of the Nijmegen breakage syndrome. Am $\mathcal{F}$ Med Genet 1989;32:425-31.

7 Curry CJR, Tsaj J, Hutchinson HT, Jaspers, NGJ, Wara D, Gatti RA. ATFresno: a phenotype linking ataxia-telangiectasia with the Nijmegen breakage syndrome. $A m \mathcal{f}$ Hum Genet 1989;45:270-5.

8 Barbi G, Scheres JMJC, Schindler D, et al. Chromosome instability and X-ray hypersensitivity in a microcephalic and growth-retarded child. Am 7 Med Genet 1991;40: 44-50.

9 Bocian E, Obersztyn E, Borowska B. Translocation $t\left(X_{\text {; }}\right.$ 14) (q28;q11.2) in a patient with clinical symptoms of 14) (q28; 11.2 ) in a patient with clinical symptoms of
Nijmegen breakage syndrome. In Vogel W, Just W, eds. 3 Tijmegen breakage syndrome. In Vogel W, Just W, eds. 3 Tagung der Geselschaft fur Humangenetik, A

10 Stoppa-Lyonet D, Girault D, Le Deist F, Aurias A. Unusual $T$ cell clones in a patient with Nijmegen breakage syndrome. F Med Genet 1992;29:136-7.

11 Green AJ, Barnes N, Billing CJ, Taylor AMR, Yates JRW The Nijmegen breakage syndrome is not an allelic form of ataxia telangiectasia. $\mathcal{F}$ Med Genet 1995;32:149-50A.

12 Savitsky K, Bar-Shira A, Galid S, et al. A single ataxi telangiectasia gene with a product similar to PI-3 kinase. Science 1995;268:1749-53.

13 Sobel E, Lange E, Jaspers E, et al. Ataxia telangiectasia: linkage evidence for genetic heterogeneity. $\mathrm{Am} \mathcal{f} \mathrm{Hum}$ Genet 1992;50:1342-8.

14 McConville CM, Byrd PJ, Ambrose HJ, Taylor AMR. Genetic and physical mapping of the ataxia telangiectasia locus on chrom.

15 Stumm M, Gatti RA, Reis A, et al. The ataxia telangiectasia variant genes 1 and 2 are distinct from the AT gene on chromosome 11q22.3. Am ₹ Hum Genet 1995;57:960-2.

16 Jaspers NGJ, Taalman RDFM, Baan C. Patients with an inherited syndrome characterized by immunodeficiency, microcephaly and chromosomal instability: genetic relationship with ataxia telangiectasia. Am $\mathcal{f}$ Hum Gene 1988;42:66-73.

17 Abadir R, Hakami N. AT with cancer. An indication for reduced radiotherapy and chemotherapy doses. BrF Radiol 1983;56:343-5.

18 Hart RM, Kimber BF, Evans RG, Park CH. Radiotherapeutic management of medulloblastoma in a pediatric patient with AT. Int $\mathcal{F}$ Radiat Oncol Biol Phys 1987;13: patient with $1237-40$.

19 Van de Kaa CA, Weemaes CMR, Wesseling P, Schaafsma in the Nijmegen breakage syndrome. Pediatr Pathol 1994; in the Nijm

20 Weemaes CMR, Smeets DFCM, van der Burgt CJAM. Nijmegen breakage syndrome: a progress report. Int $\mathscr{f}$ Radiat Biol 1994;6:S185-8.

21 Aurias A, Dutrillaux B, Lejeune J. High frequencies of inversions and translocations of chromosomes 7 and 14 in AT. Mutat Res 1980;69:369-74.

22 Jaspers NGJ, Gatti RA, Baan C, Linssen PCML, Bootsma D. Genetic complementation analysis of ataxia telangiectasia and Nijmegen breakage syndrome: a survey of 50 patients. Cytogenet Cell Genet 1988;49:259-63.

23 Komatsu K. In Gatti RA, McConville CM, eds. Meeting Report. Sixth International Workshop on Ataxia Telangiectasia. Cancer Res 1994;54:6007-10.

24 Jaspers NGJ, Van der Kraan M, Linssen PCML, Macek M, Seemanova E, Kleijer WJ. First-trimester prenatal M, Seemanova E, Kleijer WJ. First-trimester prenatal diagnosis of the Nijmegen breakage syndrome and ataxia telangiectasia using an assay of radio
thesis. Prenat Diagn 1990;10:667-74.

25 Kleijer WJ, van der Kraan M, Los FJ, Jaspers NG. Prenatal diagnosis of ataxia telangiectasia and Nijmegen breakage syndrome by the assay of radioresistant DNA synthesis Int $\mathcal{F}$ Radiat Biol 1994;66 (suppl 6):S167-74. 